\title{
Multipurpose Illumination Control
}

\author{
Kola Leleedhar Rao ${ }^{1 *}$, A Yuva Kishore ${ }^{2}$ and Kola Govardhana Giridhara Rao ${ }^{3}$ \\ ${ }^{1}$ Assistant Professor, EEE Department, Sree Vidyanikethan Engineering College \\ (Autonomous), Andhra Pradesh, India \\ ${ }^{2}$ PG Scholar, EEE Department, Sree Vidyanikethan Engineering College \\ (Autonomous), Andhra Pradesh, India \\ ${ }^{3}$ Deputy Executive Engineer, WR Department, Government of Andhra Pradesh, \\ Andhra Pradesh, India \\ 1*klr.power@gmail.com,2a.yuvakishor@gmail.com, ${ }^{3}$ gogira70@gmail.com
}

\begin{abstract}
Today, the humankind is witnessing energy crisis. This necessitates the efficient utilization of electrical energy where ever possible. Power electronics helps in accomplishing this task of efficient energy usage by providing effective control. Thyristor is an imperative family of devices in power electronic system that are commonly used in several alternating power circuits to control output power and to optimize internal power loss at the expense of switching speed. This can be achieved by providing proper control and triggering circuit to the thyristor. In this paper, a new multipurpose high power illumination control scheme that could create a foot step for energy conservation within power and infrastructural amalgam including institutional and industrial utilization is presented. A control scheme in conjunction with UJT firing circuit for controlling the conduction of SCR that acts as a power switch for high power luminary is designed and developed for three different modules under multipurpose illumination control and tested in laboratory for validation.
\end{abstract}

Keywords: Illumination, Photo sensor, Silicon controlled rectifier (SCR), Unijunction transistor (UJT)

\section{Introduction}

The lighting is considered as a structural material that can be used within a building infrastructure, domestic, institutional and industrial vicinity to help it to serve various functions. Unfortunately it is a common practice, today, to treat lighting like furniture and decoration equipment that can be added after the building has been designed and completed. Poor lighting results in severe consequences like eye-strains, headaches, accidents due to insufficient lighting or to glare. Even then, it is incredible to find that not much attention is paid to this aspect of engineering. If a huge structure like a transmission network, a dam or a bridge is to be constructed, an engineer is always consulted but if a large public building is to be illuminated, the job is normally commended to a practical man who uses rule-of -thumb methods rather than the scientific methods.

In the past, human beings passed most of their time out of door and their lighting needs were served by the nature. However, today he is spending most of his time in buildings and locale where artificial lighting plays an important role. Good lighting, apart from having aesthetic and decorative aspects, reduces accidents, increases the production in the factories and improves the general health of the community due to reduction of eye-strain. For good lighting a close cooperation among the artist, architect, the civil engineer and an illumination engineer is desired.

Recognizing the impact of light on the individual and on a global scale, the United Nations has proclaimed 2015 as the International Year of Light, citing that light plays a 
vital role in our daily lives, has revolutionized medicine and that light-based technologies promote sustainable development and provides solutions to global challenges in energy, education, agriculture and health [6].

\section{Need for Illumination Control}

High power illumination control is necessary to meet lighting requirements in residential houses, commercial complexes, offices, working places, institutions, switchyards, on-dams etc. If the lux levels of a luminary can be set according to the requirement, there could be an appreciable savings in the energy.

The illumination control can be achieved by incorporating power electronic devices in the circuit, so that the output of the high power luminary can be controlled. The following are three types of power devices [2, 3 and 5] that can be used as switches: Power diode; Power transistor; Thyristor.

Power diode is a two terminal, uncontrolled device in which losses are more when compared to other power devices. Hence it is not suitable for the illumination control. Power Transistor is a three terminal fully controlled device which is not suitable for desired line commutated circuits. Hence it is also not suitable for illumination control. Thyristor in particular, SCR is a three terminal turn-on controlled device suitable for desired line commutation circuits. It works well at power frequencies. Hence SCR is a suitable device for multipurpose high power illumination control. Triac-Diac based illumination controllers by their trade name lighting dimmers are commercially available in the market but are limited to low power applications.

According to National Building Code (NBC) [1] the different locations and tasks are grouped into the following sections: Offices, Schools and Public Buildings; Industrial Buildings and Process; Surgeries and Hospitals; Hotels, Shops, Restaurants and Homes.

\section{Design of Control Circuit}

\subsection{UJT Firing Circuit}

The basic block diagram of UJT firing circuit for attaining manual illumination is shown in Figure 1. It consists of a diode rectifier block, firing circuit block, isolation transformer, lamp load and SCR.

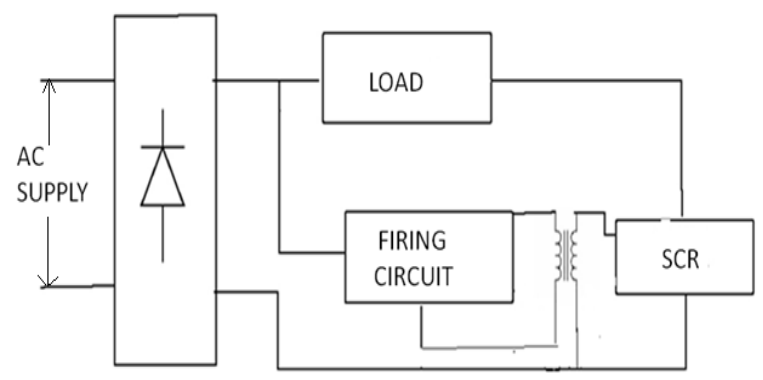

Figure 1. Figure Basic block diagram of Illumination Control

\subsection{Other Sub Circuits}

\subsubsection{Stabilization Block}

The stabilization block consists of a zener diode and a resistor. The resistor is used to obtain required voltage to zener by dropping the remaining voltage across it. Zener diode is used to maintain $15 \mathrm{~V}$ voltage to the firing circuit. 


\subsubsection{Photo Sensor Block for Automatic Illumination Control}

The photo sensor block, a novel scheme designed and developed for automatic illumination control is shown in Figure 2. It consists of a light dependent resistor (LDR) and light emitting diode (LED). When LDR1 is exposed to day light, its resistance gets lowered and the voltage across LED drops down leading it to emit less intensity of light. This light is focused on LDR2 which is used instead of variable resistor in UJT firing circuit. As the intensity of light emitted by LED is low, the LDR2 attains high resistance so that the lamp load output gets lowered. Similarly during night hours, light incident on LDR1 becomes negligibly small so that it attains high resistance and the voltage across LED rises leading it to emit high intensity of light. As the intensity of light emitted by LED is high, the LDR2 attains low resistance so that the lamp load output gets increased.

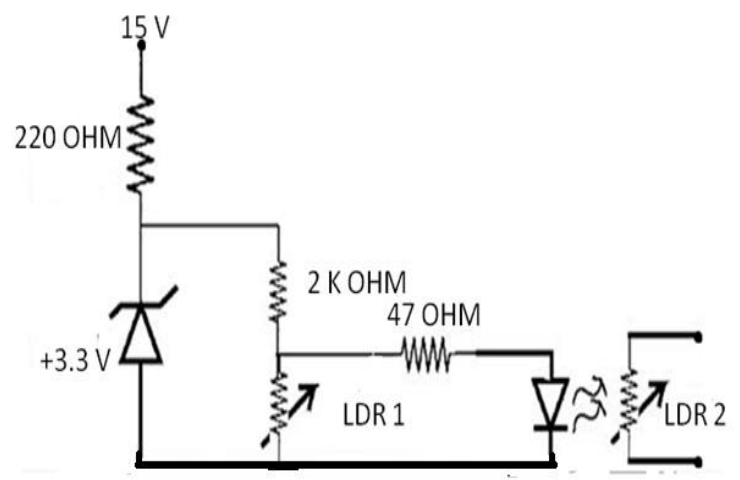

Figure 2. Photo sensor block of Automatic Illumination Control

\section{Multipurpose Illumination Control}

The developed novel circuit for multipurpose illumination control is shown in the Figure 3.

\subsection{Manual Illumination Control Module}

The manual control of illumination is obtained by making rotor switch to get in contact with corresponding switching position $\mathrm{M}$. The formed circuit consists of a diode bridge rectifier, zener diode, loading resistor, current limiting resistor, variable resistor, capacitor, UJT and its base resistances, SCR and lamp. The variations of output voltage or the voltage across the lamp to be controlled, $\mathrm{V}_{\mathrm{GK}}$ (gate to cathode control voltage) i.e., output voltage of UJT and capacitor voltage for different firing angles are shown in Figures 4 to 6 . By observing the waveforms in Figures 4 to 5, it can be understood that, minimum illumination is attained at maximum firing angle and maximum illumination is attained at minimum firing angle. The obtained specifications of output voltage and capacitor voltage at different firing angles for manual control are presented in Tables 1 and 2 respectively. And corresponding variations are depicted in Figure 7 and Figure 8 respectively.

\subsection{Automatic Illumination Control (AIC) Module}

The automatic control of illumination is obtained by making rotor switch to get in contact with corresponding switching position AL. During day hours, as the sunlight focuses on the LDR1, it attains low resistance causing low or insufficient voltage to appear across LED, thereby making LED to emit no light. As LDR2, a control element of control circuit is facing LED and as there is no light focusing on it, its resistance increases, thereby making UJT firing circuit unable to trigger the SCR. As a consequence 
lamp remains un-glowing. And during night hours, as no light will focus on the LDR1, it will attain high resistance causing increase in the intensity of light emitted by LED there by creating low resistance on the LDR2 because of which lamp glows automatically. If the light focusing on LDR1 is partial, it will attain medium resistance causing the partial variation in the light intensity by the LED there by creating medium resistance within LDR2. As a consequence light will glow partially. By performing this control strategy, it is observed that, with proper focusing of light on the LDR1, proper control to the firing angle of the SCR can be attained, which controls illumination of the lamp automatically. By this module balanced illumination is achieved.

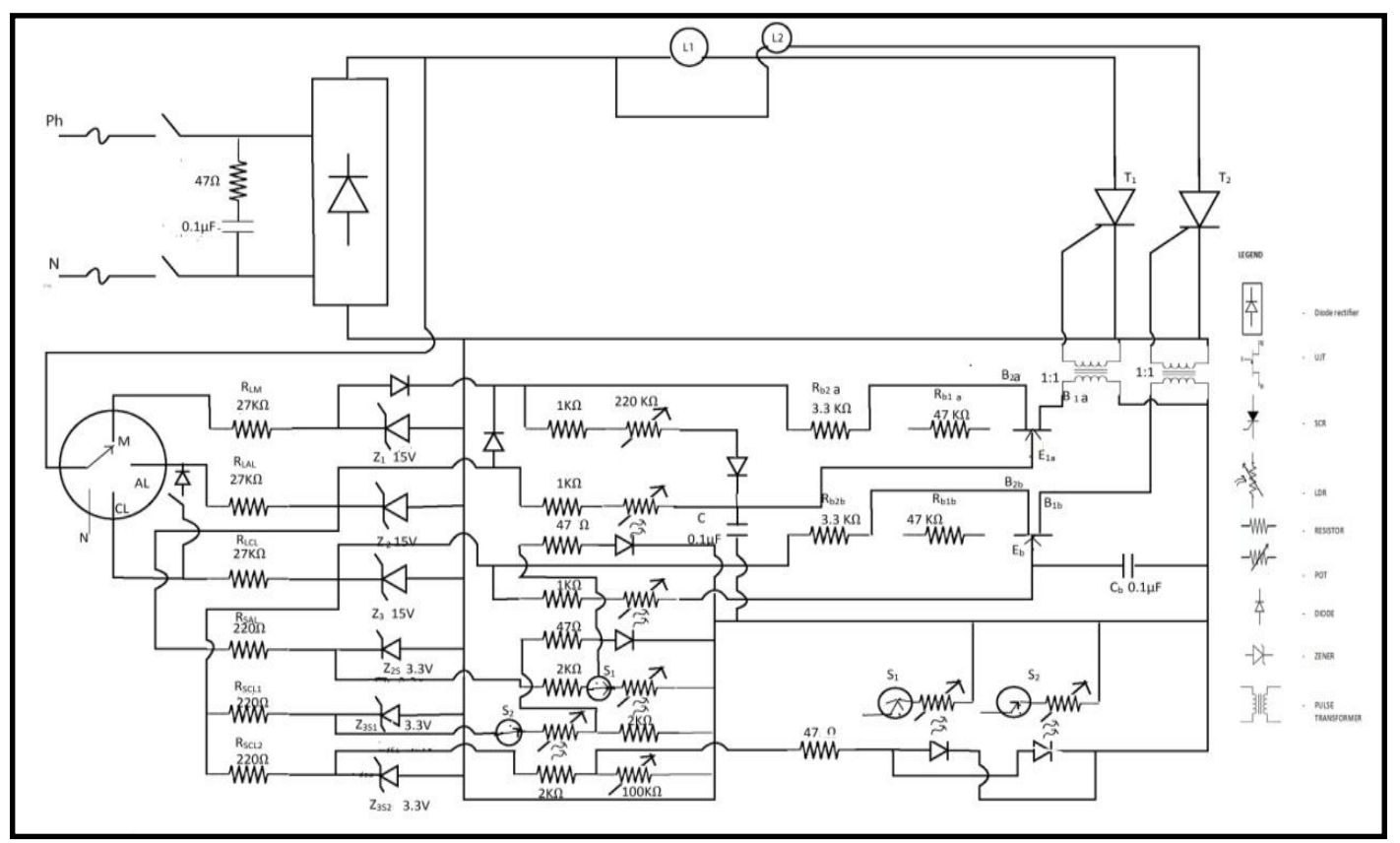

Figure 3. Developed Circuit for Automatic Illumination Control

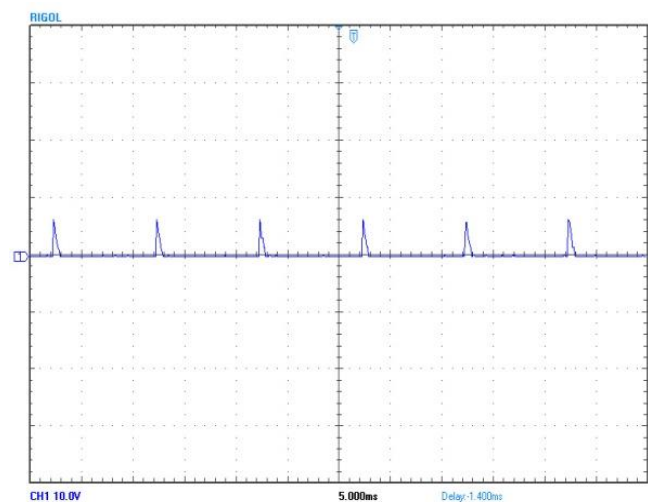

Figure 4a. Output Voltage at Maximum Firing Angle

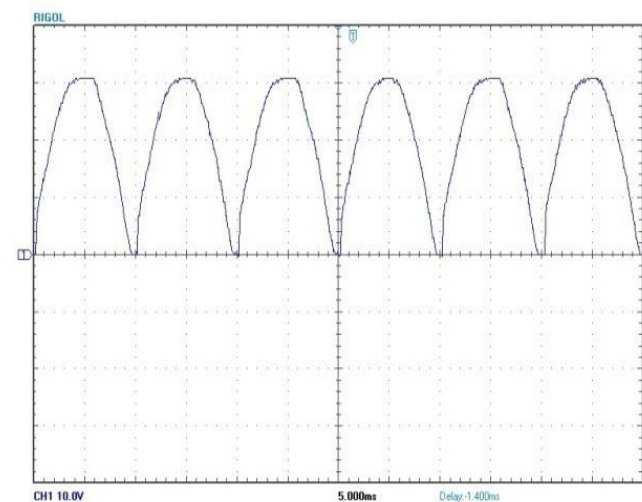

Figure 4b. Output Voltage at Minimum Firing Angle 


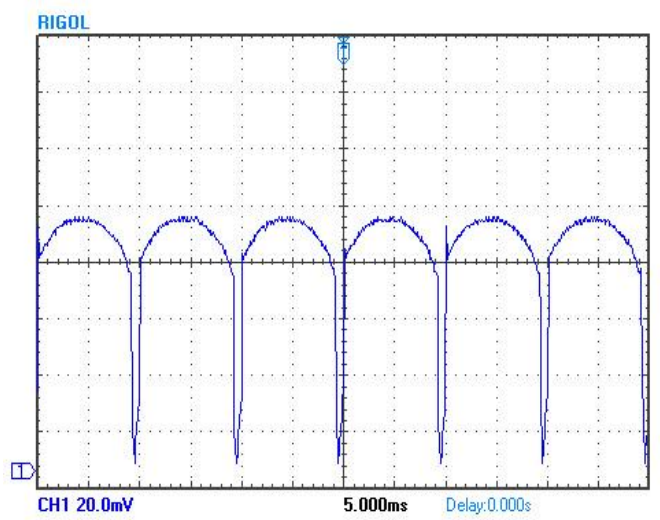

Figure 5a. $\mathrm{V}_{\mathrm{GK}}$ at Maximum Output

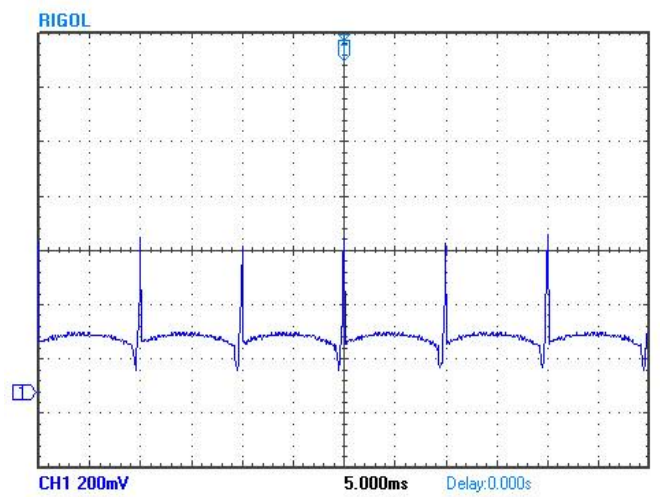

Figure 6a. Voltage Across Capacitor at Maximum Output

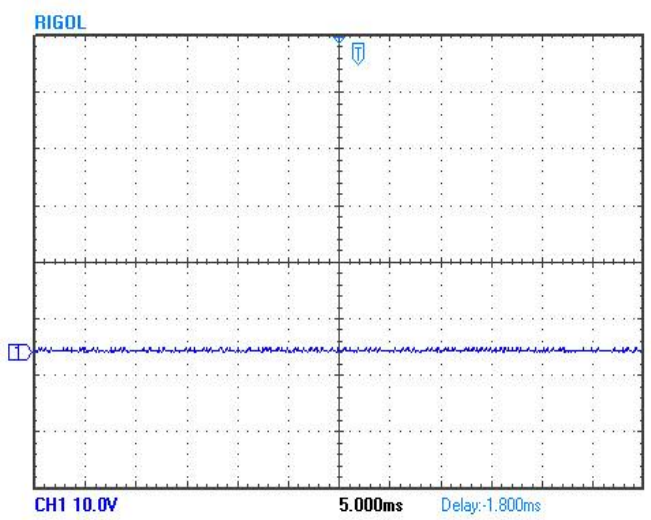

Figure $5 \mathrm{~b} . \mathrm{V}_{\mathrm{GK}}$ at Minimum Output

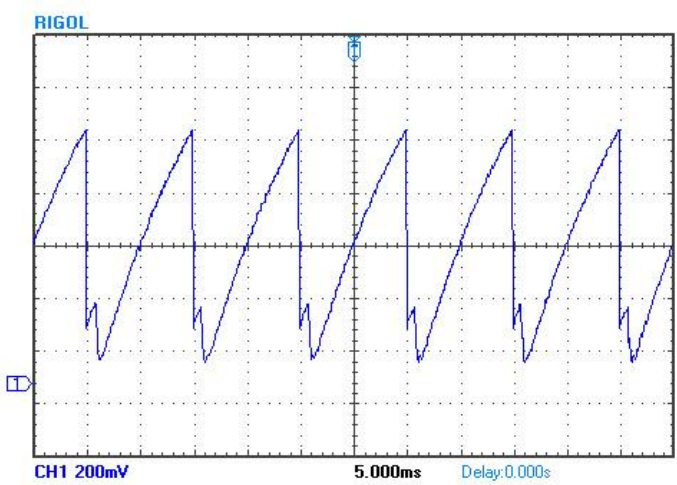

Figure 6b. Voltage Across Capacitor at Minimum Output

Table 1. Obtained specifications of Output Voltages by MIC

\begin{tabular}{|l|c|c|c|}
\hline & Max firing angle & $90^{\circ}$ Firing angle & Min firing angle \\
\hline $\mathrm{V}_{\mathrm{pp}}(\mathrm{V})$ & 0.8 & 30.8 & 31.2 \\
\hline $\mathrm{V}_{\max }(\mathrm{V})$ & 0.4 & 30.4 & 30.8 \\
\hline $\mathrm{V}_{\min }(\mathrm{mV})$ & -0.4 & -400 & -400 \\
\hline $\mathrm{V}_{\mathrm{avg}}(\mathrm{V})$ & -0.088 & 11.5 & 16.9 \\
\hline $\mathrm{V}_{\text {rms }}(\mathrm{V})$ & 0 & 17 & 21 \\
\hline Period$(\mathrm{ms})$ & $9.90 \mathrm{E}+37$ & 10 & 10 \\
\hline Pulse Width+(ms) & $9.90 \mathrm{E}+37$ & 3.8 & 5.8 \\
\hline Pulse Width-(ms) & $9.90 \mathrm{E}+37$ & 6.2 & 4.4 \\
\hline
\end{tabular}

Table 2. Obtained Specifications of Capacitor Voltages by MIC

\begin{tabular}{|l|c|c|c|}
\hline & Min-output & 54 $^{0}$ firing & Max-output \\
\hline $\mathrm{V}_{\mathrm{pp}}(\mathrm{V})$ & 0.88 & 0.896 & 0.504 \\
\hline $\mathrm{V}_{\max }(\mathrm{V})$ & 0.96 & 0.976 & 0.576 \\
\hline $\mathrm{V}_{\text {avg }}(\mathrm{V})$ & 0.519 & 0.54 & 0.202 \\
\hline $\mathrm{V}_{\text {rms }}(\mathrm{V})$ & 0.585 & 0.598 & 0.208 \\
\hline Period & $1.00 \mathrm{E}+01$ & 1.76 & 10 \\
\hline Pulse width(ms) & $5.00 \mathrm{E}+00$ & 1.12 & 0 \\
\hline Pulse width(ms) & $5.20 \mathrm{E}+00$ & 0.64 & 9.8 \\
\hline
\end{tabular}


The variations of output voltage or voltage across the lamp to be controlled, UJT output voltage and voltage across the capacity during no light and day light condition are shown in the Figures 9 to 11. The obtained specifications of output voltage and capacitor voltage at different firing angles for automatic illumination control are presented in Tables 9 and 10 respectively and corresponding variations are depicted in Figure 12, Figure 13 respectively. The variations of output voltage or voltage across the lamp to be controlled, UJT output voltage and voltage across the capacity during no light and day light condition are shown in the Figures 9 to 11. The obtained specifications of output voltage and capacitor voltage at different firing angles for automatic illumination control are presented in Tables 3 and 4 respectively and corresponding variations are depicted in Figures 12 and 13 respectively.



Figure 7. Output Voltage Variation

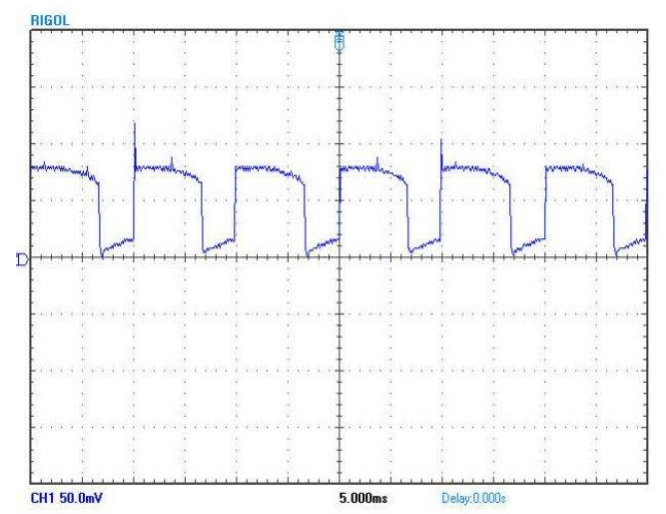

Figure 9a. UJT Output Voltage at No Light

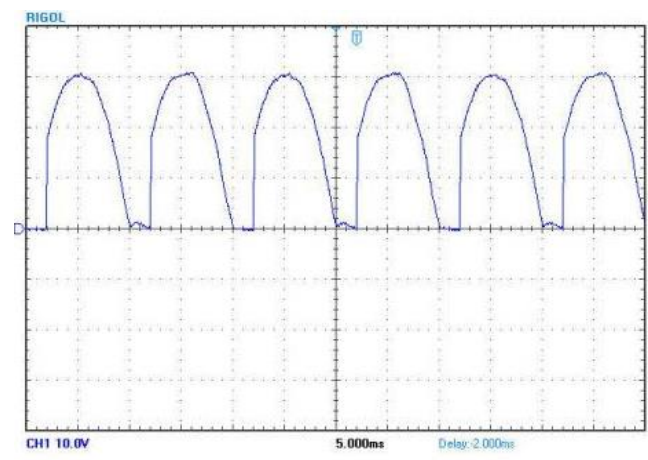

Figure 10a. Output Voltage at No Light

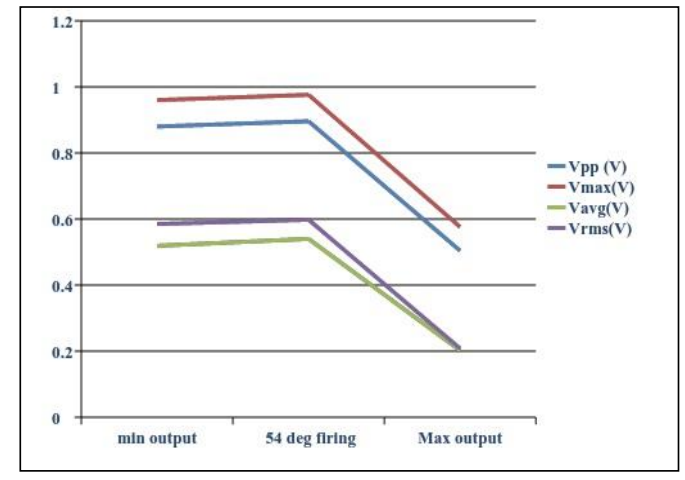

Figure 8. Capacitor Voltage Variation



Figure 9b. UJT Output Voltage at Day Light

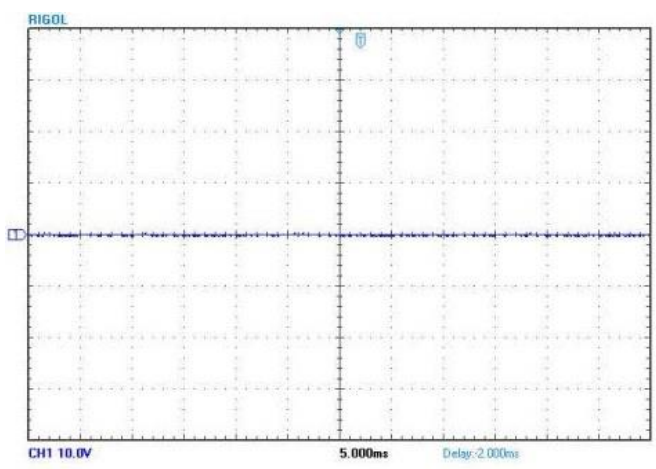

Figure 10b. Output Voltage at Day Light 


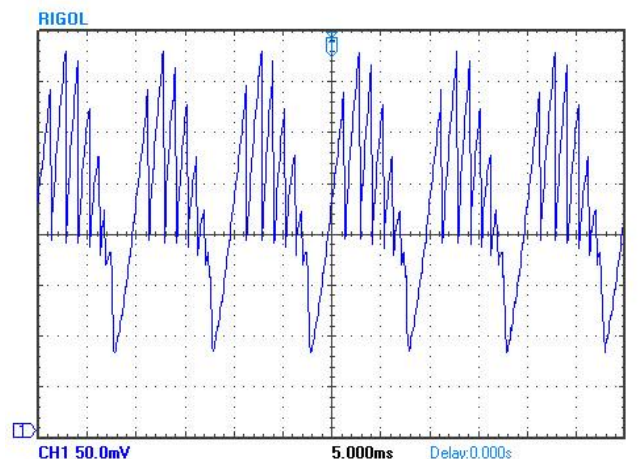

Figure 11a. Voltage Across Capacitor at No Light

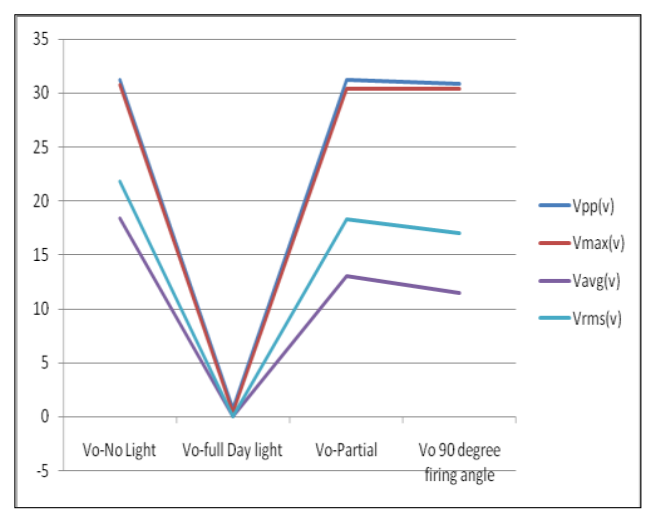

Figure 12. Obtained Output Voltage Variation by AIC

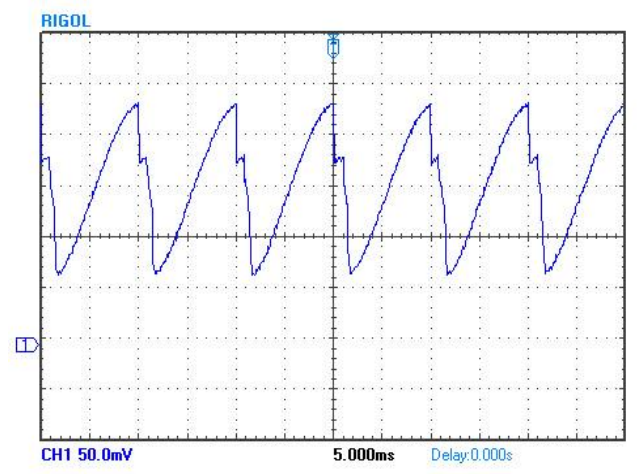

Figure 11b. Voltage Across Capacitor at Day Light

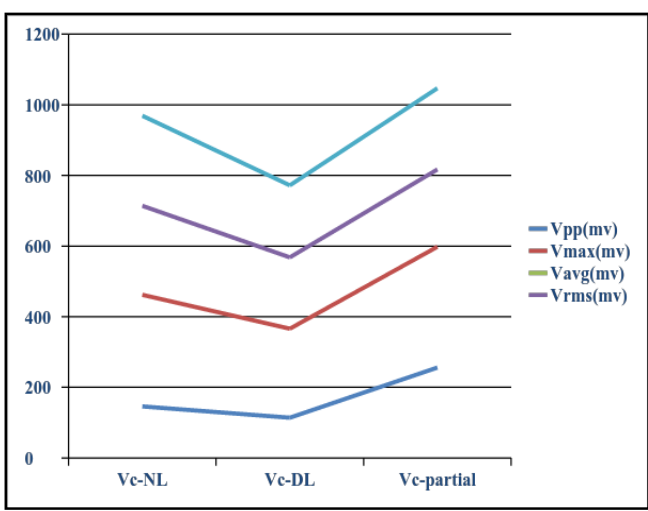

Figure 13. Obtained Capacitor Voltage Variation by AIC

Table 3. Obtained Specifications of Output Voltages by MIC

\begin{tabular}{|l|c|c|c|c|}
\hline & $\begin{array}{c}\mathbf{V}_{\mathbf{o}}-\text {-No } \\
\text { Light }\end{array}$ & $\begin{array}{c}\mathbf{V}_{\text {o-full }} \\
\text { Day light }\end{array}$ & $\mathbf{V}_{\mathbf{o}}$-Partial & $\begin{array}{c}\mathbf{V}_{\mathbf{o}}-\mathbf{- 9 0}^{\mathbf{0}} \\
\text { firing angle }\end{array}$ \\
\hline $\mathbf{V}_{\text {pp }}(\mathbf{V})$ & 31.2 & 0.8 & 31.2 & 30.8 \\
\hline $\mathbf{V}_{\text {max }}(\mathbf{V})$ & 30.8 & 0.4 & 30.4 & 30.4 \\
\hline $\mathbf{V}_{\text {min }}(\mathbf{m V})$ & -400 & -400 & -400 & -400 \\
\hline $\mathbf{V}_{\text {avg }}(\mathbf{V})$ & 18.4 & -0.0008 & 13 & 11.5 \\
\hline $\mathbf{V}_{\text {rms }}(\mathbf{V})$ & 21.8 & 0 & 18.3 & 17 \\
\hline
\end{tabular}

Table 4. Obtained Specifications of Capacitor Voltages by MIC

\begin{tabular}{|c|c|c|c|}
\hline & $\mathrm{V}_{\mathrm{c}}-\mathrm{NL}$ & $\mathrm{V}_{\mathrm{c}}-\mathrm{DL}$ & $\mathrm{V}_{\mathrm{c}}$-partial \\
\hline $\mathrm{V}_{\mathrm{pp}}(\mathrm{mV})$ & 146 & 114 & 256 \\
\hline $\mathrm{V}_{\max }(\mathrm{mV})$ & 316 & 252 & 342 \\
\hline $\mathrm{V}_{\min }(\mathrm{mV})$ & 170 & 138 & 86 \\
\hline $\mathrm{V}_{\mathrm{avg}}(\mathrm{mV})$ & 252 & 202 & 219 \\
\hline $\mathrm{V}_{\mathrm{rms}}(\mathrm{mV})$ & 255 & 204 & 230 \\
\hline
\end{tabular}

\subsection{Complementary Switching}

Complimentary switching of two lamps is attained by a photo sensitive main controller (PSMC) and two complimentary sub controllers. PSMC is achieved by a light source, 
may be sun light. Light emitted by the photo active element within PSMC is focused on photo sensitive elements within sub controllers. Complimentary lighting will be emitted by the photo active elements of two sub controllers that intern vary the photo sensitive resistance of firing circuit complimentarily which controls the firing angles of SCRs associated with two power circuits. This facilitates complimentary lighting, as if illumination of first lamp is high, the illumination of second lamp will be low and vice versa. It is best suited for applications where both indoor and outdoor lighting can be controlled simultaneously based on day light condition. The circuit diagram for complementary switching automatically is obtained by making rotor switch to get in contact with corresponding switching position CL. During the night hours no light will be focused on the parallel combination of LDRs (LDR2 and LDR2a). Hence they will attain high resistance. Coming to the first part of the circuit, due to high resistance attained, the voltage developed within the potential circuit formed will be higher there by activating LED1. The light emitted by LED1 will be focused on LDR1, because of which the later resistance gets reduced thereby triggering corresponding SCR at lower firing angle. Thus lamp1 glows. On the other hand the performance of second part of the circuit will be reverse and the lamp2 remains OFF. Converse is the case during day light conditions.

\section{Visual Exhibits of AIC}

Experimental setup and visual exhibits using RIGOL DS1000E DSO, of designed Multipurpose Illumination Control Modules are shown in Figures 14 and 15.

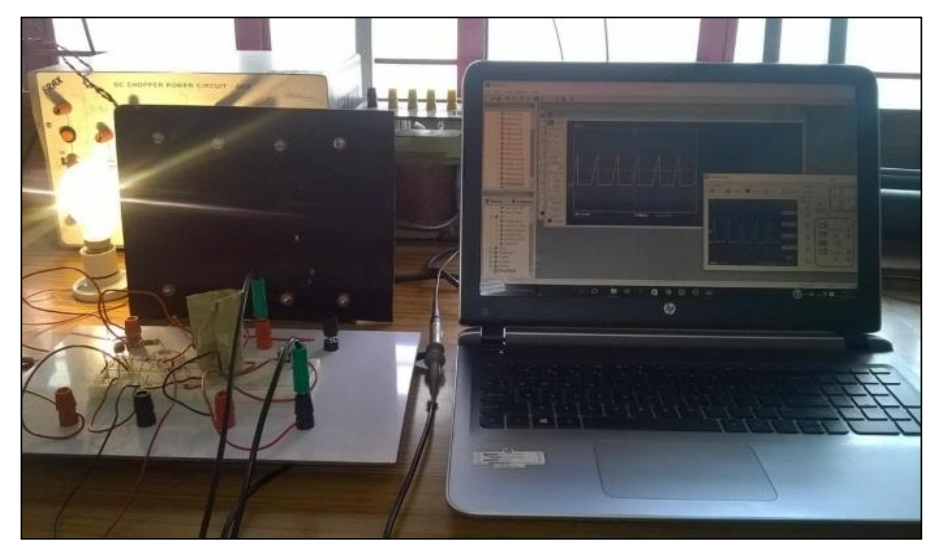

Figure 14. Experimental Setup and Visual Exhibit of AIC

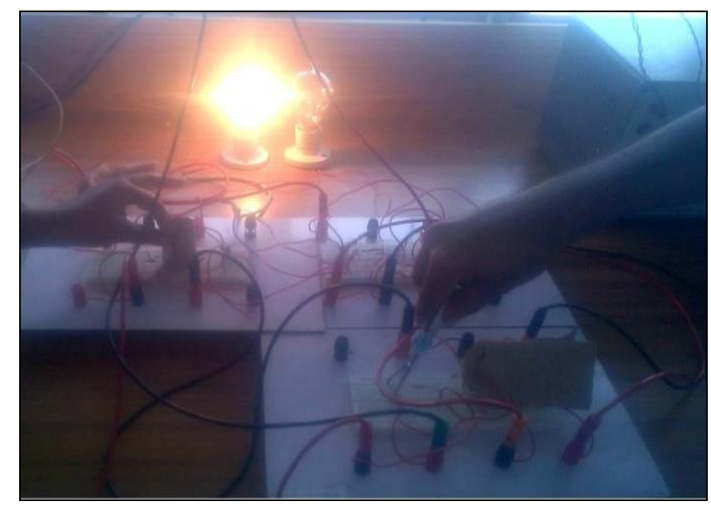

Figure 15a. Experimental Setup and Visual Exhibit of AIC

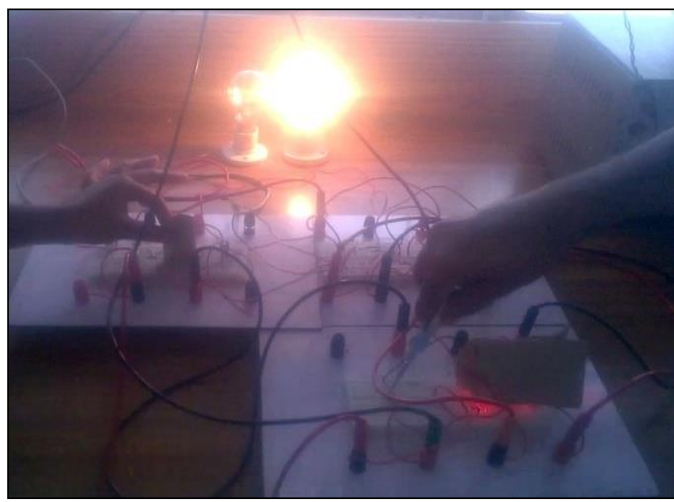

Figure 15b. Experimental Setup and Visual Exhibit of AIC 


\section{Estimation of Savings in Energy Consumption}

A case study on energy savings is performed by considering a room of $4 \times 3$ square feet. Energy consumption based on NBC standard lux level requirement is estimated, assuming that considered room can be utilized as a normal room, reading room, living room and sleeping room. Different luminaries with $12 \%$ luminous efficacy are assumed to serve the above said purposes and monthly energy consumption is estimated and tabulated as shown in Table 5.

Table 5. Estimation of Monthly Energy Consumption

\begin{tabular}{|c|c|c|c|c|c|}
\hline & $\begin{array}{c}\text { Assumed } \\
\text { Hours of } \\
\text { use }\end{array}$ & $\begin{array}{c}\text { Required } \\
\text { light } \\
\text { intensity in } \\
\text { Lux }\end{array}$ & Lumens & $\begin{array}{c}\text { Output in } \\
\text { Watts }\end{array}$ & $\begin{array}{c}\text { Energy } \\
\text { consumption per } \\
\text { month in kWh }\end{array}$ \\
\hline Normal room & 24 & 400 & 459 & 38.25 & 27.54 \\
\hline Reading room & 4 & 400 & 446 & 37.12 & 4.47 \\
\hline Sleeping room & 6 & 30 & 33.4 & 2.78 & 5 \\
\hline Living room & 14 & 200 & 223 & 18.6 & 7.8 \\
\hline
\end{tabular}

A single room serving different purposes can be fulfilled by using single lamp with automatic control circuit module instead of separate lamps for achieving desired lux level. And it was found that about $22 \%$ of energy consumption can be saved if multipurpose illumination control circuit module is used with a single lamp instead of separate lamps for fulfilling the concern purpose of room utilization.

\section{Conclusions}

Multipurpose illumination control, a novel scheme with photo sensitive main and sub controllers in conjunction with UJT firing circuit for controlling the conduction of SCR is designed, developed and validated experimentally. Three modules have been developed namely manual illumination control, automatic illumination control and complementary switching. In case of manual illumination control, illumination of a room can be varied as per the desired usage, viz., living, studying, sleeping and etc., maintaining standard lux level as per NBC standards. A single luminary with SCR control circuit replaces different luminaries serving different purposes thereby saving appreciable percentage of energy consumption. Automatic illumination control facilitates the variation of illumination of indoor as well as outdoor lighting based on natural day light existence. On the other hand, complementary switching control of two lamps saves the power consumption by serving two different purposes at a time. Hence by the proposed multipurpose illumination control scheme, energy consumption can be reduced creating a foot step for energy conservation.

\section{Acknowledgments}

Authors wishes to acknowledge Mr. Kappa Charan and his team for their support during experimental stage of proposed multipurpose illumination control modules.

\section{References}

[1] National Building Code of India.

[2] M. H. Rashid, "Power Electronics", Prentice Hall of India Publishers Ltd., (2009).

[3] P. S. Bimbhra, "Power Electronics", Khanna Publishers, New Delhi, (2002). 
[4] A. K. Sawhney, "A Course in Electrical and Electronics Measurements and Instrumentation", Dhanpat Rai and Sons, New Delhi, (1995).

[5] K. L. Rao and Ch. Saibabu, "Theory of Power Electronics", SChand \& Co. Ltd., New Delhi, (2009).

[6] http://www.light2015.org.

[7] Datasheets of TYN612 - SCR, W10M - RECTIFIER, 2N2646 - UJT, IN4744A - ZENER DIODE.

\section{Authors}

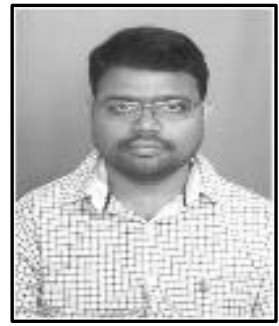

Kola Leleedhar Rao is working as Assistant Professor in the Department of EEE, Sree Vidyanikethan Engineering College (Autonomous), Tirupati, Andhra Pradesh, India. He did Post Graduation, M.Tech, from JNTUA College of Engineering (Autonomous) Anantapur and pursued Bachelor's degree, B.Tech, from S.V. University, Tirupati. He acquired total 10 years of experience in teaching and industry particularly in the area of 400kV EHV Substation \& Transmission Line constructions. His areas of research interest include Smart Power Systems \& Renewable Energy based Distributed Generation, Power Systems impacts of Future Energy Systems Integration, and Application oriented Electrical systems design and development.

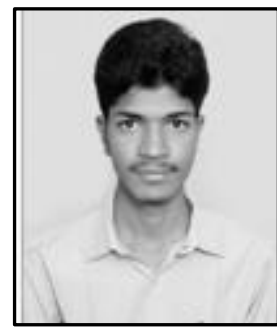

A. Yuva Kishore, is Post Graduation Scholar in the Department of EEE, Sree Vidyanikethan Engineeering college (Autonomous), Tirupathi, Andhra Pradesh, India. He did his Graduation B.Tech from JNTUA college of Engineering, Pulivendula. His areas of interest are Power system Dynamics, Power Electronic convertors and Renewable Energy Sources.

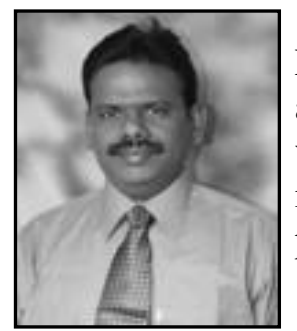

Mr. Kola Govardhana Giridhara Rao is a Deputy Executive Engineer working in WR Department' SRBC Division, Kurnool, and Government of Andhra Pradesh, India. He has 20 years of versatile experience in the field of irrigation, power \& infrastructure and designed \& executed several multipurpose projects useful to the humankind. 